\title{
Comfort properties of cotton, acrylic and polypropylene/ nettle union fabrics
}

Neha Garg, Harinder Kaur Saggu and Kanwaljit Kaur Brar

Received: 15.11.2017; Revised: 24.04.2018; Accepted: 11.05.2018

See end of the paper for authors' affiliations

Neha Garg

Department of Apparel and

Textile Science, College of Home

Science, Punjab Agricultural

University, Ludhiana (Punjab)

India
ABSTRACT : The textile industry for designing and producing new textiles from time to time. The efforts were taken to develop Eco-friendly and biodegradable fibres to control non-polluting environment. Nettle plant have been used as food, fodder and raw material in cosmetics, medicines, industry and bio-dynamic agriculture. Many experiments have been conducted not only in developing commercial textiles using nettle, but also in the growth and propagation of the crop in the most sustainable manner. The nettle union fabrics were constructed to study the properties of fabric. To construct nettle union fabric, the nettle yarn was used as weft with cotton, acrylic and polypropylene yarn as warp. In the study, the fabrics were prepared with three different weave (plain, twill and basket weave). Union fabric was much cheaper in cost compared to pure nettle fabric. Those woven fabrics were tested for physical and mechanical properties analyzed. Further, data were evaluated to find out the influence of physical and mechanical properties.

KEY WORDS: Nettle union fabric, Cotton, Acrylic, Polypropylene, Physical, Mechanical properties.

- HOW TO CITE THIS PAPER : Garg, Neha, Saggu, Harinder Kaur and Brar, Kanwaljit Kaur (2018). Comfort properties of cotton, acrylic and polypropylene/nettle union fabrics. Asian J. Home Sci., 13 (1) : 352-356, DOI: 10.15740/HAS/AJHS/13.1/352-356. Copyright@ 2018: Hind Agri-Horticultural Society. 